\title{
Research on Evaluation System of Smart City Construction Based on Analytic Hierarchy Process
}

\author{
Feng $\mathrm{He}$ \\ Baoshan Campus of Shanghai University in China \\ m18351996052@163.com
}

Keywords: Smart City; AHP; Evaluation Index System

\begin{abstract}
Smart City is a higher city development level after the appearance of industrial city, information city and digital city. Based on the Analytic Hierarchy Process (AHP) method, this paper constructs an evaluation index system in terms of Smart City development which is suitable to the national conditions of China, synthetically considering factors like Smart Economy, Smart Population, and Smart Environment and so on. It provides helpful references for measuring the development level and progress of Smart City, and further promoting the construction of Smart City.
\end{abstract}

\section{Introduction}

Recently, obtaining information indirectly through internet, TV, and mobile phone becomes more and more common with the advancement of society and the improvement of urban residents' living standard. These make worldwide information collection and communication more convenient. As a result, the number of people who like to spend time surfing on the internet has surged.

However, indirectly getting information through internet is pale in comparison with being personally on the scene. In addition, the purpose of urban public space which is served as meeting place is to encourage people to participate and play positive personal roles. Characteristics closely relating to urban public space include the potential for personal experience, face-to-face conversation, and the experience of existing and unpredictable city life.

Nonetheless, these factors are easily overlooked in modern urban design, as people pay more attention to the construction of infrastructure like road and rail networks. Along with the increase of vehicle population, many public spaces have been replaced by temporary parking lots leaving less public space for urban residences to take their leisure and social activities.

Smart City, further development on the foundation of digital city, is a product of higher stage of urban informatization. Taking account of the concept of modern urban development, Smart City is an important opportunity for China to transform its urbanization model since it can integrate existing city resources, improve the efficiency of resource utilization, and improve government's capacity in public service and administration. There are already many cities in the world who are planning Smart City like Tokyo, San Francisco, Amsterdam, Ottawa, Santiago, Brisbane, Bangalore and so on. In China, there are also hundreds of cities and regions who have proposed the construction of Smart City.

\section{Literature Review}

Research on Purpose, Meaning and Application of Smart City. In 2010, Xibo Wu and Zaigao Yang [1] pointed out that developing Smart City is helpful to improve the effectiveness of city operation, contribute to the rise and expansion of new industries, promote a new round of technological innovation, finally to create a better city life. Sam Allwinkle and Peter Cruickshank [2] indicated that Smart City plays a critical role in urban progress. They stated that the threat to urban development is an important driving force of Smart City development.

In the article "Smart City: Technology Promotes Harmony", Shengwu Wu and Guoqing Yan [3] divided the application of Smart City into ten fields, which include Smart Government, health care, education, transportation, security, energy, corporation, community, public service, and logistic. 
Another article called "Big Smart City: Urban Competitiveness in 2020" written by Xinzhi Qian[4], put forward different ten categorizations of Smart City application covering smart transportation, electricity, finance, vehicle, hospital, school, corporation, agriculture, family, and community.

Research on Technology Used in Smart City. Shengwu Wu and Guoqing Yan [3] in their article "Smart City: Technology Promotes Harmony" thought that technology used in Smart City include internet, data storage and development, remote sensing and monitoring system, visualization and virtual implementation. In "Smart City Dictionary", Shiwei Wang [5] thought that technology used in Smart City contain knowledge in four fields: ubiquitous network, Internet of Things, internet, and cloud computing.

Research on Smart City Evaluation Index System. In 1993, Jipeng Jin [6] created the measuring system of social informatization on the basis of Porat's method, when he measured the information industry in Jilin Province. This method, also called comprehensive information industry strength law, contains six categories and 252 indexes. It is the first more complete social informatization evaluation system.

In 1998, Yixin Zhong [7] created information synthesis index method with the help of Porat's method and informatization index method. It contained five categories as information industry level, information infrastructure equipped level, information infrastructure use capacity, information subject ability, and information consumption level. They were further refined into 18 indexes.

Xianfeng Deng [8] divided Smart city into a 2-class evaluation index system. The first class included fundamental area, smart industry, smart service, and human wisdom. While the second class contained 23 more detailed indexes.

This paper will establish a set of key indicators of intelligent city construction through scientific method to construct a multi-level evaluation index system which conforms to China's national conditions. Through expert investigation and analytic hierarchy process (AHP), we can determine the weight of each index and finally complete the scientific and reasonable wisdom Urban construction evaluation index system for the establishment of China 's wisdom for the city to provide a reference.

\section{The Establishment of Evaluation Index System}

Procedure. This paper via drawing lesson from methods and research framework commonly used at home and abroad, develops five procedures to establish Smart City evaluation index system. First, identify the hierarchical structure of the index system. Through summarizing and refining the classification framework, this paper establishes 3-class index system. The first class is Smart City. While the second class divides Smart City into 5 elements including Smart Economy, Smart Population, Smart Government, Smart Environment, and Smart Life. The third class includes specific indexes introduced below.

Second, decide the principle for index selection. According to the requirement of Smart City development, this paper establishes the following four principles: scientific principle, universality principle, accessibility principle, and operation principle.

Third, determine the range of index selection. This paper combines domestic and overseas existing evaluation systems to determine the scope of index selection.

Fourth, index selection. Following the index selection principles, project team members score initially selected indexes, eliminate non-conforming indexes, and finally select 29 indexes as the third class index.

Fifth, specialists score those indexes through paired comparison and applying AHP to determine the weight of those indexes.

The AHP Model Construction. We judge the matrix through the AHP model construction, evaluating the results by sufficiently searching the understanding and comprehensive feedback of experts who have high prestige in Smart City field. Also, refer to Table 1 Scales of Judgment Matrix Definition, we assign each index the corresponding weight by comparing the importance of each pair. 
Table 1 Scales of judgment matrix definition

\begin{tabular}{|c|c|}
\hline Scale & Meaning \\
\hline 1 & Have the same importance \\
\hline 3 & The former is a litter more important than the latter \\
\hline 5 & The former is important than the latter \\
\hline 7 & The former is more important than the latter \\
\hline 9 & The former is significantly more important than the latter \\
\hline $2,4,6,8$ & Intermediate value of the judgment above \\
\hline
\end{tabular}

According to the steps of AHP and the scale of relevant matrix judgment, each index in the system is scored by comparing in a pair and the judgment matrix is constructed. The following is the calculation process of each judgment scale.

To calculate the normalized relative importance vector that compare each index with the former (Criterion level), we use the weighted average method, as follow:

$$
\begin{aligned}
& \omega_{j}=\sum_{i=1}^{n} \frac{a_{i j}}{n}, j=1,2,3, \ldots, m \\
& \omega_{j}^{\prime}=\frac{\omega_{j}}{\sum_{i=1}^{n} \omega_{j}}, j=1,2,3, \ldots, m
\end{aligned}
$$

Among them, $\mathrm{n}$ is the number of judges, $\mathrm{m}$ is the evaluation of the index, $\omega_{j}$ is the weighted average of the JTH index, $\omega_{j}^{\prime}$ is the ith a judge for the first $\mathrm{j}$ a score index weight.

Determine the Weight of the Index. AHP, a qualitative, quantitative, systematic, and hierarchical analysis method, works effectively in determining the weight of the index. It mainly contains three procedures. Firstly, establish 3-class index system. The first class is Smart City. The second class includes Smart Economy, Smart Population, Smart Government, Smart Environment, and Smart Life. At last, the third class includes those 29 indexes selected in relation to the second-class elements.

Secondly, construct the judgment matrix. In order to quantitatively distinguish the importance of each class index and make the index system has broad social participation, this paper uses knowledge of people belonging to government, universities, and enterprises. They are specialists and active participants in Smart City research, planning, developing and management aspects, with comprehensive understanding of the connotation of Smart City.

Thirdly, determine the weight of the index. This paper calculates the maximum eigenvalue and eigenvector of each judgment matrix through the use of MATLAB 7.0 software. Then, all eigenvectors are normalized to get the weight of each index. 
Table 2 Smart City development level evaluation index system and weight

\begin{tabular}{|c|c|c|c|}
\hline $\begin{array}{l}\text { Target } \\
\text { layer(A) }\end{array}$ & Rule layer(B) & Index layer(C) & Weight \\
\hline \multirow{29}{*}{$\begin{array}{l}\text { Smart City } \\
\text { Index A }\end{array}$} & \multirow{4}{*}{$\begin{array}{l}\text { Smart Economy } \\
\text { B1 }(0.141)\end{array}$} & X1 Per capita disposable income & 0.362 \\
\hline & & X2 GDP growth rate & 0.206 \\
\hline & & X3 Service sector share of GDP & 0.270 \\
\hline & & X4 Local fiscal revenue & 0.163 \\
\hline & \multirow{7}{*}{$\begin{array}{l}\text { Smart Population } \\
\text { B2(0.239) }\end{array}$} & X5 Educational expenditure share & 0.121 \\
\hline & & X6 Patent applications per ten thousand & 0.084 \\
\hline & & $\begin{array}{l}\text { X7 Invention applications per ten thousand } \\
\text { people }\end{array}$ & 0.088 \\
\hline & & X8 Per capita education investment & 0.213 \\
\hline & & X9 Scientific research personnel proportion & 0.134 \\
\hline & & $\begin{array}{l}\text { X10 number of college students per ten } \\
\text { thousand people }\end{array}$ & 0.163 \\
\hline & & X11 Total labor force & 0.197 \\
\hline & \multirow{6}{*}{$\begin{array}{l}\text { Smart Government } \\
\text { B3(0.119) }\end{array}$} & X12 Information disclosure index & 0.176 \\
\hline & & X13 Construction rate of emergency system & 0.143 \\
\hline & & X14 Social security penetration & 0.328 \\
\hline & & X15 Natural disaster warning release & 0.101 \\
\hline & & X16 Building digital energy saving rate & 0.092 \\
\hline & & $\begin{array}{l}\text { X17 Environmental quality automation } \\
\text { monitoring rate }\end{array}$ & 0.160 \\
\hline & \multirow{6}{*}{$\begin{array}{l}\text { Smart } \\
\text { EnvironmentB4(0.383) }\end{array}$} & X18 Green GDP share of GDP & 0.217 \\
\hline & & X19 Motor Vehicle Tail Gas Passing Rate & 0.102 \\
\hline & & X20 The average ambient noise & 0.110 \\
\hline & & X21 Garbage disposal ability & 0.099 \\
\hline & & X22 Green coverage ratio & 0.292 \\
\hline & & X23 Energy repeat utilization rate & 0.180 \\
\hline & \multirow{6}{*}{ Smart Life B5(0.118) } & $\begin{array}{l}\text { X24 The number of doctors per ten thousand } \\
\text { people }\end{array}$ & 0.153 \\
\hline & & X25 Unemployment rate & 0.347 \\
\hline & & X26 Rail transit operation range & 0.093 \\
\hline & & X27 Transit site coverage & 0.085 \\
\hline & & X28 Internet usage cost & 0.144 \\
\hline & & X29 Internet penetration & 0.178 \\
\hline
\end{tabular}

Test the Model's Consistency. Due to the fact that raters only roughly judge the Judgment Matrix in real assessment, inconsistent results may appear. According to the AHP theory, we need to calculate consistency. The equation is shown below:

$$
\text { C.R. }=\frac{\text { C.I. }}{R . I .}
$$


Consistency Index Equation:

$$
\text { C.I. }=\frac{\lambda_{\max }-n}{n-1}
$$

Among them, $\lambda_{\max }$ is the biggest characteristic value. C.I. measures the deviation from the consistency of judgment matrix. R.I. means consistency index. C.R. is the consistency ratios.

When consistency ratios for all levels of matrix are all less than 0.1 , every matrix has satisfying consistency.

Table 3 The largest eigenvalue with consistency index and the consistency ratio

\begin{tabular}{|c|c|c|c|c|c|c|}
\hline Matrix & $\mathrm{A}$ & $\mathrm{B} 1$ & $\mathrm{~B} 2$ & $\mathrm{~B} 3$ & $\mathrm{~B} 4$ & $\mathrm{~B} 5$ \\
\hline & 5.0930 & 4.1717 & 7.3643 & 6.4743 & 6.0564 & 6.2854 \\
\hline $\mathrm{n}$ & 5.0000 & 4.0000 & 7.0000 & 6.0000 & 6.0000 & 6.0000 \\
\hline R.I. & 1.1200 & 0.8900 & 1.3200 & 1.2400 & 1.2400 & 1.2400 \\
\hline C.R. & 0.0208 & 0.0643 & 0.0460 & 0.0765 & 0.0091 & 0.0460 \\
\hline
\end{tabular}

We can see in Table 3, all C.R. are less than 0.1. Judgment Matrix possesses consistency. In other words, the result of our model materiality calculation is logically reasonable.

Interpretation of Results. As shows in Table 2, the order of the five elements in the second index class is Smart Environment (0.383), Smart Population (0.239), Smart Economy (0.141), Smart Government (0.119), and Smart Life (0.118). It indicates that Smart Environment and Smart Population rank first and second respectively, which indicates that government should not promote economy development at the expense of environment instead should pay more attention to environmental governance and cultivation of talents in the process of building Smart City. Moreover, Smart Life is an auxiliary element which also deserves some attention to ensure Smart City development, though it ranks last.

In Smart Economy, the weight of disposable income per capital is the highest. In Smart Population, the weight of education investment per capital is the highest. In Smart environment, the weight of Green coverage ratio is the highest. In Smart Government, the weight of social security penetration is the highest. In Smart Life, the weight of unemployment rate is the highest.

\section{Summary}

This paper uses the analytic hierarchy process (AHP) to determine the weight of the indexes at all levels, building a set of evaluation index system of wisdom which accords with the situation of China in the city. The superiority of this index system is systematically covers the important connotation of Smart City; Grade of each index weight is given through the expert, to overcome the traditional index system for city limits of longitudinal and transverse comparison between the cities. The conclusion based on this index system, combining with the current process of our Smart City construction, the author suggested the development direction of future Smart City construction in our country are as follows:

First, overall planning, we should build the urban system of wisdom. Smart City construction is a systematic project, which needs the organic combination of city of each subsystem, the formation of the wisdom of city operation system, in order to realize the comprehensive perception of city each organism and each other.

Secondly, combine hard and soft, and find new ways to apply Smart. Smart application is the most direct reflection of Smart City development, and the fundamental guarantee to improve existing management model, improve government service capacity, and make people's lives more convenient.

Lastly, this index system can be used in periodic monitoring assessment to ensure development direction and progress. From a vertical view of the application of the index system, each city can 
compare with this index system to master its overall and partial progresses of development, find out its strength and weakness, confirm future development direction, and formulate plans. From a horizontal view, this index system can be used in government, enterprises, and residents researches to rank cities to different grades by assessing their smart development levels. This is helpful for the leading cities to create a demonstration effect driving the development of Smart City.

\section{References}

[1] Xibo Wu, Zaigao Yang. Smart City Concept and Future Urban Development[J]. Urban Development Research.2010(11):56-60.

[2] Sam Allwinkle; Peter Cruickshank. Creating Smart-er Cities: An Overview[J]. Journal of Urban Technology. Volume: 18 Issue: 2 2011-04: 1-16.

[3] Shengwu Wu, Guoqing Yan. Smart City: Technology Promotes Harmony[M]. Hangzhou: Zhejiang University Press, 2010.

[4] Xinzhi Qian. Big Smart City: Urban Competitiveness in 2020[M]. Nanjing: Jiangsu People’ s Publishing House, 2011.

[5] Shiwei Wang, et al. Smart City Dictionaries[M]. Shanghai: Shanghai Lexicographical Publishing House, 2011.

[6] Jipeng Jin, et al. Measuring the Information Industry in Jilin Province[J]. Journal of The China Society for Scientific and Technical Information. 1993(6): 433-444.

[7] Yixin Zhong. The Theory and Method of Measuring the Informatization Level[M]. Beijing: Economic Science Press, 2000: 187-189.

[8] Xianfeng Deng. Research on The Evaluation Index System of "Smart City"[J]. Development Research, 2010(12): 111-116. 